Bulletin d'Histoire Contemporaine de l'Espagne

$50 \mid 2016$

Les intellectuels en Espagne, de la dictature à la démocratie (1939-1986)

\title{
Del papel a la pantalla. El recorrido mediático de la inteligencia antifranquista
}

Du papier à l'écran. Le parcours médiatique de l'intelligentsia franquiste

From paper to the screen. The media route of the pro-Franco intelligentsia

Juan Pecourt

\section{OpenEdition}

\section{Journals}

Edición electrónica

URL: http://journals.openedition.org/bhce/565

DOI: 10.4000/bhce.565

ISSN: 1968-3723

Editor

Presses Universitaires de Provence

Edición impresa

Fecha de publicación: 1 diciembre 2016

Paginación: 111-125

ISSN: 0987-4135

Referencia electrónica

Juan Pecourt, «Del papel a la pantalla. El recorrido mediático de la inteligencia antifranquista », Bulletin d'Histoire Contemporaine de l'Espagne [En línea], 50 | 2016, Publicado el 09 octubre 2018, consultado el 22 septiembre 2020. URL : http://journals.openedition.org/bhce/565 ; DOI : https:// doi.org/10.4000/bhce.565 


\title{
Del papel a la pantalla. El recorrido mediático de la inteligencia antifranquista
}

\author{
Juan PECOURT
}

Universitat de València

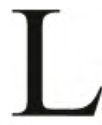

os intelectuales, en su sentido moderno, surgen en las sociedades europeas de finales del siglo XIX, sobre todo después del Affaire Dreyfus, y responden a unas condiciones institucionales y políticas específicas que no pueden trasladarse impunemente a cualquier tipo de sociedad'. Históricamente, muchas sociedades han funcionado sin la presencia de los intelectuales, posiblemente la mayoría. Por tanto, existen unas "condiciones de origen", que muestran elementos comunes y divergentes entre las distintas culturas nacionales y políticas, favorables a su desarrollo. Entre las condiciones necesarias para que aparezcan, una de las más importantes se encuentra en el ámbito de los medios de comunicación. No olvidemos que el intelectual surge con el desarrollo de la prensa de masas: en ese momento, las tribunas que le proporcionan los medios le permiten trascender el mundo de los especialistas y comunicarse con sus conciudadanos. Por ello, puede afirmarse con certeza que los cambios en los medios suelen tener un impacto directo en las funciones del intelectual. Como a lo largo del siglo XX el progreso tecnológico ha diversificado los medios y remodelado la esfera pública, las distintas generaciones intelectuales no han tenido más remedio que adaptarse a estos cambios, y adoptar diferentes figuras acordes a los tiempos. Del mismo modo que los regímenes políticos (dictaduras, democracias, etc.) condicionan la presencia de los intelectuales, también los diferentes entornos mediáticos (prensa, radio, televisión y, más recientemente, Internet) han moldeado sus comportamientos.

Dados estos condicionantes, consideramos que para comprender el papel de los intelectuales en un momento histórico, además de tener en cuenta su vinculación con el régimen político o la estructura económica, es necesario observar su relación con los medios de comunicación. Esta relación se refleja en dos aspectos fundamentales que formarán la base del análisis que se presenta:

1 Existen definiciones más abiertas que consideran intelectual a todos aquellos que se dedican a la producción de ideas, como en el trabajo Jacques LE Goff, Los intelectuales en la Edad Media, Madrid, Gedisa, 1986. Sin embargo la mayor parte de los trabajos tienden a dar un gran peso al contexto nacional especifico de los intelectuales. Sobre el nacimiento de los intelectuales en Francia ver Christophe Charle, Naissance des intellectuels, 1880-1900, Paris, Editions de Minuit, 1990, Y sobre su nacimiento en España, Carlos SERrano, «Los intelectuales en 1900: ¿ensayo general?» en Serge Salaün y Carlos Serrano (eds.), 1900 en España, Madrid, Espasa-Calpe, 1991, p. 85-106; Carlos Serrano (ed.), El nacimiento de los intelectuales en España, Marcial Pons, Madrid, 2001; y Santos Julı́, «Literatos sin pueblo: la aparición de los intelectuales en España», Studia Histórica. Historia Contemporánea, núm. 16, 1998, p. 107-121. Un estudio comparativo a nivel europeo en Christophe CHARLE, Les intellectuels en Europe au XIX siècle, París, Seuil, 1996. 
a) En primer lugar, la aparición de los intelectuales depende del desarrollo de órganos institucionales (revistas, editoriales, centros de estudio, etc) relativamente independientes respecto a los poderes políticos, económicos y religiosos ${ }^{2}$. El intelectual moderno se caracteriza por expresarse desde una posición de cierta autonomía y por su capacidad para dirigirse directamente a las capas cultas de la población. Esta autonomía puede utilizarse para colaborar con el poder, a cambio de ciertos beneficios y prebendas, o para enfrentarse a él y tratar de introducir cambios en la organización política y social.

b) En segundo lugar, y relacionado con lo anterior, la autonomía del intelectual no es solamente el resultado de su voluntad individual sino que depende del desarrollo de una esfera pública en la que puedan encauzarse diálogos y debates sobre los temas de interés general, que faciliten la apertura de canales de comunicación entre la sociedad civil y el poder. Las características específicas de este espacio han sido estudiadas por teóricos como J. Habermas ${ }^{3}$, quienes insisten en la importancia de los medios de comunicación como uno de sus sustentos básicos.

Por supuesto, el carácter maleable de los intelectuales, y sus variantes históricas, también es cierto para la inteligencia española. Nos encontramos con un momento de auge -los años de la Segunda República (aunque el empuje ya venía de antes) ${ }^{4}-$ y unos años de oscuridad -el periodo del primer franquismo-, en los que podríamos afirmar que los intelectuales como tales prácticamente desaparecen de la escena. En este caso, el papel de los medios también será muy importante, tanto en los momentos de apogeo como de decadencia. Entre otros factores, en el primer franquismo los grandes referentes públicos de la cultura desaparecen por dos razones que nos interesa resaltar: a) no existen órganos de expresión que mantengan su independencia respecto del poder, y b) no existe un espacio público y libre de discusión. Aparecen otras figuras que realizan tareas equivalentes, como el sacerdote, el propagandista o el ideólogo, pero no podemos hablar de intelectuales en su sentido moderno. No existen las condiciones básicas para que puedan actuar libremente en el espacio público.

Tomando esta premisa como punto de partida, mostraremos de manera sintética cómo, después de dos décadas de retraimiento (años 40 y 50), comienza a recuperarse el espacio social de los intelectuales ${ }^{5}$. Se trata de un proceso sin duda complejo y contradictorio

2 Pierre Bourdieu, Las reglas del arte. Génesis y estructura del campo literario, Barcelona, Anagrama, p. 487-503.

3 Jürgen HaBermas, Historia y crítica de la opinión pública, Barcelona, Gustavo Gili, 1989.

4 Sobre la efervescencia de los intelectuales durante la República ver Jean BÉcARUd y E. López CAMPILLO, Los intelectuales españoles durante la Segunda República, Madrid, Siglo XXI, 1978, Paul AuBERT, «Los intelectuales en la Segunda República» en Ayer, núm. 40, 2000. Sobre el exilio de los intelectuales después de la guerra puede consultarse José Luis ABELLÁn, El exilio español de 1939, Madrid, Taurus, 1976-1978. Sobre la destrucción de la ciencia después de la guerra civil ver José Manuel SÁnCHEZ RoN. Cincel, Martillo y piedra. Historia de la ciencia en España (siglos XIX y XX), Madrid, Taurus, 1999; Luis E. Otero, La destrucción de la ciencia en España y la politica de depuraciones en la Universidad, Madrid, Editorial Complutense, 2006.

5 La bibliografia sobre el «páramo culturale» de la posguerra y la progresiva reconstrucción de la razón es bastante amplia. Un botón de muestra serian los trabajos de Elías DiAz, El pensamiento español en la era de Franco, Madrid, Tecnos, 1983; Sheila MANGINI, Rojos y rebeldes. La cultura de la disidencia durante el franquismo, Barcelona, Anthropos, 1987; Juan Pablo Fusı, Un siglo de España. La cultura, Madrid, Marcial Pons, 1999, Jordi Gracia, Estado y cultura. El despertar de una conciencia crítica bajo el franquismo, Barcelona, península, 1996; Jordi Gracia, La resistencia silenciosa. Fascismo y cultura en España, Barcelona, Anagrama, 2004; Santos JulıA, Historias de las dos Españas, Madrid, Taurus, 2004; Ismael SAZ, España contra España. Los nacionalismos franquistas, Madrid, Marcial Pons, 2003; Zira Box, España. Año Cero. La construcción simbólica del franquismo, Madrid, Alianza, 
que requeriría un análisis más profundo del que permiten estas páginas. De todas formas, trataremos de apuntar algunas líneas generales y ciertas contradicciones básicas que condicionaron su evolución y cambio en los años de la Transición política, centrándonos en su relación con los medios y el público. A partir de los años 50, y a diferencia de los partidos políticos clandestinos, cuyos debates y consignas no salían de los círculos reducidos de militantes y activistas, algunas publicaciones (primero en ámbitos universitarios y luego en el seno del mercado cultural) lograron escapar de las convenciones de la cultura oficial y empezaron a difundir ideas ajenas al ideario franquista y los intereses de la dictadura. Desde estas plataformas, y de forma progresiva, las formas de oposición fueron intensificándose y haciéndose más diversas. Poco a poco, gracias a su labor, se asentaron las bases de una esfera pública en la que empezarán a generalizarse las ideas del cambio político y social.

\section{La recuperación del espacio perdido}

En el libro Los intelectuales y la transición politica (2008) traté de mostrar cómo durante el segundo franquismo se reconstruye el entramado social en el que se sitúan los intelectuales, al tiempo que se produce la «reconstrucción de la razón» (E. Díaz) y se recuperan formas de pensamiento que habían sido expulsadas de las grandes instituciones culturales (prensa, editoriales, universidades, academias, centros de investigación). Al principio, este espacio se sitúa en el ámbito de los medios de comunicación, del que surge un conjunto de publicaciones que se marcan el objetivo, con limitaciones innegables, de reivindicar ideas proscritas en el seno de la cultura oficial. En sus momentos iniciales se trata de publicaciones estudiantiles situadas bajo el paraguas del movimiento falangista, pero paulatinamente estas empresas asumirán objetivos más ambiciosos, y se separarán de los poderes que en un principio las habían tutelado para acercarse a las fuerzas políticas de la oposición. Bajo un sistema de prensa fuertemente controlado por los poderes del régimen ${ }^{6}$, en estas iniciativas puede encontrase el fermento social que posibilita: (a) la aparición de los intelectuales en su expresión moderna, y (b) la influencia de este colectivo en la vida civil.

Al centrarme en el espacio social que van tejiendo las nuevas generaciones de pensadores y activistas pretendo delinear cómo se reconquista la autonomía de los medios y se reconstruye las plataformas de apoyo de la inteligencia, ese espacio que había sido devastado por la guerra, y en consecuencia cómo se va recuperando poco a poco la noción moderna del intelectual, la del escritor independiente que interviene en la vida pública desde una posición de cierta autonomía, cuya aspiración es generar debates y difundir valores de carácter laico, civil e ilustrado ${ }^{7}$. El esfuerzo de reconstrucción será fruto del trabajo de varias generaciones, empieza con el esfuerzo aún tentativo y exploratorio de la generación del 36 , para continuar después con los posicionamientos más desarrollados y decididos de las generaciones posteriores.

2010; Ferrán Gallego y Francisco MoRENTE (eds,), Rebeldes y reaccionarios. Intelectuales, fascismo y derecha radical en Europa (1914-1956), Barcelona, El Viejo Topo, 2011; Abdón MATEos, Historia del antifranquismo, Barcelona, Flor del viento, 2011.

6 Javier Terrón, La prensa española durante el régimen de Franco, Madrid, CIS, 1981; Elisa ChUliA, El poder y la palabra. El régimen de Franco ante la prensa y el periodismo, Madrid, Biblioteca Nueva, 2001.

7 Elías DiAz, De la Institución a la Constitución. Política y cultura en la España del siglo XX, Madrid, Trotta, 2009, p. 195-219. 
El papel de la generación de la guerra, a pesar de sus orígenes falangistas, es muy importante, porque ellos inician los debates teóricos e ideológicos (empiezan a hablar de nuevo del liberalismo, del laicismo, o facilitan la introducción de los debates de la época, como el existencialismo) que después continuarán otros quizá con mayor contundencia y claridad. Pero, además, la generación del 36 aporta los recursos sociales necesarios para la reconstrucción institucional de la esfera pública (ellos tienen la autoridad, las conexiones institucionales, el prestigio científico-social para hacerlo). En el ambiente autoritario de la época, iniciar cualquier empresa cultural implicaba superar toda una serie de trabas administrativas y burocráticas, meticulosamente establecidas por la censura franquista, que debían sortearse con la ayuda de personas que mantuvieran una cierta influencia en el régimen ${ }^{8}$. Algunas de las primeras iniciativas, como la revista El Escorial (1940-1950) de D. Ridruejo, aún estaban muy influidas por la ortodoxia del régimen, pero con los años surgieron proyectos que lograron mantener un mayor grado de autonomía. Este es el caso de Boletín Informativo (1954-1964), dirigida por E. Tierno Galván y publicada desde la Universidad de Salamanca, que logró abrir espacios para la libertad de pensamiento impensables en otros ámbitos. Liberada en gran medida de la censura política y religiosa, Boletín Informativo introdujo los grandes debates que se estaban desarrollando en esos momentos, en el ámbito de las ciencias sociales, en otras sociedades occidentales ${ }^{9}$. Por otro lado, en los años 50 aparece también la revista Theoria (1952-1956), gracias al impulso de M. Sánchez-Mazas, que, junto al Boletín Informativo, logró romper con el anti-cientifismo de la ortodoxia franquista y se lanzó a la importación de metodologías científicas y las corrientes de la filosofia analítica. Las exigencias teóricas y metodológicas de estas publicaciones pronto se transformarán en demandas de transparencia y democracia en el ámbito político.

Las revistas académicas y científicas no fueron las únicas en abrir el espacio de discusión libre, también participaron ciertos ámbitos académicos, centros de estudios y otras organizaciones más o menos formales. Algunos ejemplos tempranos, como el Instituto de Humanidades (1948-1950), fundado por J. Marías junto a J. Ortega y Gasset ${ }^{10}$, no tuvieron mucho éxito, pero más tarde sí se lanzaron otros proyectos con repercusiones importantes. Este tipo de inciativas necesitaban de permisos y autorizaciones para ponerse en funcionamiento, por lo que el apoyo institucional de los antiguos falangistas también era fundamental. En el libro Memoria Democrática, por ejemplo, J. Vidal-Beneyto reconoce los desvelos de P. Laín Entralgo para que los jóvenes sociólogos de CEISA pudieran superar los obstáculos constantes y los cierres gubernamentales impuestos por el franquismo, que incluían visitas periódicas a la inquietante Dirección General de Seguridad, con lo que les permitió materializar proyectos destinados a difundir las ciencias sociales y el pensamiento

8 Sobre el funcionamiento de la censura ver Antonio BenEyto, Censura y politica en los escritores españoles, Barcelona, Euros, 1975; Gabriel Cisquiella y otros, Diez años de represión cultural, La censura de los libros durante la ley de prensa, Barcelona, Anagrama, 1977; Manuel ABELLAN, Censura y creación literaria en España (1939-1976), Barcelona, Península, 1980; y Román GuBERN, La censura: función politica y ordenamiento jurídico bajo el franquismo (1936-1975), Barcelona, Península, 1981, Eduardo Ruiz Bautista (coord.), Tiempo de censura. La represión editorial durante el franquismo, Gijón, Trea, 2008. Al mismo tiempo, el franquismo organizó un poderoso aparato de propaganda para neutralizar las ideas y colectivos disidentes, como muestra Carme Molinero, La captación de las masas: politica social y propaganda en el régimen franquista, Madrid, Cátedra, 2005.

9 Elias Diaz, El pensamiento español en la era de Franco, Madrid, Tecnos, 1983.

10 Gregorio Moran, El maestro en el erial. Ortega y Gasset y la cultura del franquismo, Barcelona, Tusquets, 1998, p. 259-279. 
crítico $^{11}$. Apoyados por intelectuales disidentes del franquismo como Laín Entralgo, J. L. Aranguren, E. Tierno Galván o J. L. Sampedro, los jóvenes organizaron seminarios en los que se difundían teorías inéditas en España, vinculadas a diversos campos de las ciencias sociales: L. A. Rojo, J. Vidal-Beneyto, R. Tamames, R. Morodo, E. Díaz, C. Moya, L. García San Miguel, etc. ${ }^{12}$. Quizás las nuevas generaciones se encontraban ya bastante alejadas de los postulados de algunos de sus mentores, pero aún así los seniors les allanaron el camino, permitiéndoles llevar a cabo sus proyectos. Estos proyectos, además, generaron sus propias publicaciones destinadas a difundir sus actividades.

Entre los antiguos falangistas que hicieron un mayor esfuerzo por aglutinar a los intelectuales más jóvenes, proporcionándoles plataformas de expresión adecuadas, merece destacarse el caso de J. Ruiz-Giménez ${ }^{13}$. En el pasado había tenido una gran influencia en el régimen, pero progresivamente se fue desvinculando de éste para acercarse a las reivindicaciones democráticas. A pesar de su alejamiento mantuvo su posición social y su capacidad de maniobra, lo que le permitió fundar empresas decisivas como Cuadernos para el Diálogo, una iniciativa cultural de amplio calado (en un principio revista mensual y más tarde también editorial) que facilitó el acceso de generaciones más jóvenes, portadoras de nuevos valores y perspectivas, a un espacio público en proceso de reconstrucción. La mayor parte de los participantes eran estudiantes o licenciados de derecho, como G. PecesBarba, Juan M. Bandrés, L. Torres, E. Barón, O. Alzaga, N. Sartorius, J.L. Cebrián, o T. de la Cuadra Salcedo, etc. Otros, aunque tenían una formación jurídica empezaban a orientarse hacia otras ramas de las ciencias sociales: E. Díaz, J. Rodríguez Aramberri, José J. Toharia, J. M. Maravall, I. Sotelo, L. García San Miguel, C. Moya, R. Morodo, Alfonso C. Comín, M. Castells, V. Pérez-Díaz, etc ${ }^{14}$. En sus páginas se encuentran las primeras generaciones de científicos sociales en España, un colectivo que había realizado cursos de formación en el extranjero y tratará de adoptar las metodologías científicas a la resolución de los problemas sociales, alejándose de las perspectivas más metafísicas que caracterizaran a las generaciones anteriores, incluidos sus maestros. La publicación difundió una visión de la convivencia basada en el diálogo entre las diferentes sensibilidades sociales al tiempo que demandaba un mayor pluralismo ideológico. Acechada por la censura, la revista difundió múltiples debates en la sociedad española como las reflexiones en torno al Estado de Derecho, las implicaciones políticas del Concilio Vaticano II, el sindicalismo y el movimiento obrero, la cuestión de las nacionalidades, etc.

Por tanto, consideramos que la importancia de la generación del 36 no se encuentra solamente en su capacidad de mantener el legado liberal, sino también en una posición institucional que le permitió abrir ese espacio («abrir la lata» según la expresión futbolística) a la contra de los sectores más ortodoxos del franquismo. De este modo, aparecen las primeras organizaciones culturales ligadas a la oposición, que en un primer momento son sobretodo revistas dedicadas a temas políticos y sociales (Cuadernos para el diálogo y Triunfo en Madrid, Destino en Barcelona, Cuadernos de Ruedo Ibérico en París,

11 José Vidal-Beneyto, Memoria democrática, Madrid, Foca, p. 15

12 Ibid., p. 83.

13 La influencia de Ruiz-Giménez en las nuevas generaciones se muestra en la obra colectiva V.V.A.A., La fuerza del Diálogo. Homenaje a Joaquín Ruiz-Giménez, Madrid, Alianza Editorial, 1997.

14 Javier MuÑoz Soro, Cuadernos para el Diálogo (1963-1976). Una historia cultural del segundo franquismo, Madrid, Marcial Pons, 2006, p. 74 
etc) y algunos centros de estudios e investigación ${ }^{15}$. El papel que juegan las revistas en la construcción inicial de estos espacios no es sorprendente ya que tienen grandes ventajas estratégicas frente a otro tipo de iniciativas. En primer lugar, a diferencia de otras empresas culturales y periodísticas, su confección es relativamente barata, y en segundo lugar, tienen una función dual que otros medios no pueden asumir; por un lado, se trata de publicaciones especializadas, centradas en debates de tipo político y/o cultural, que no aspiran a competir con la prensa generalista (Pueblo, ABC, La Vanguardia Española), totalmente controlada por la cultura oficial del franquismo y dirigida hacia los públicos masivos, y por el otro, también aspiran a una cierta generalidad, es decir, que no son solamente revistas especializadas o académicas, sus debates aspiran a trascender las esferas académicas y conectar con los intereses y expectativas de las capas cultas de la sociedad. Por su parte, los partidos políticos de la clandestinidad, como hemos comentado anteriormente, tienen grandes dificultades para difundir sus ideas más allá del círculo de los militantes (además de crear sus propias publicaciones de partido $\mathrm{o}^{16}$, el recurso a las revistas del antifranquismo será una forma de alcanzar esa difusión). A partir de estos medios comenzará a reconstruirse el espacio público y empezará a tomar forma la figura del intelectual como conciencia moral de la sociedad.

El momento culminante del proceso de reconstrucción lo podemos situar en los últimos años del franquismo y los comienzos de la transición. El franquismo trató de frenar su desarrollo con medidas espectaculares como el cierre (1971) y la posterior voladura (1972) de la sede del periódico Madrid, aunque los intentos resultaron inútiles. En el ámbito de la prensa de masas, el vespertino Madrid, dirigido por el periodista A. Fontán, era una punta de lanza de las corrientes de oposición; desde sus páginas se lanzaban mensajes de gran ambigüedad semántica que podían interpretarse como reivindicaciones sutiles de los principios democráticos. El famoso artículo de R. Calvo Serer «Retirarse a tiempo: no al general De Gaulle» ha quedado como un hito de este tipo de periodismo comprometido y caracterizado por diversos niveles de lectura ${ }^{17}$. La clausura del vespertino madrileño fue un triunfo momentáneo de la censura, pero de ningún modo logró frenar la expansión del espacio público ${ }^{18}$. A partir de esos momentos, las revistas Triunfo y Cuadernos para el Diálogo se convirtieron en los grandes referentes del antifranquismo y, a pesar de las sanciones constantes y las incautaciones, lograron difundir una cultura democrática

15 La importancia de las revistas en la articulación de la oposición al franquismo ha quedado plasmada en las siguientes publicaciones: José-Carlos MAINER, «La revista Escorial en la vida literaria de su tiempo», Insula, 271, 1969; Laureano BoNet, La revista «Laye»: estudio y antología, Barcelona, Península, 1988; Carles Gel y Josep Maria Huertas, Las tres vidas de Destino, Barcelona, Anagrama, 1991; José Antonio Gonzalez Casanova (ed.), La revista El Ciervo, Barcelona, Península, 1992; Alicia Alted y Paul Aubert (ed.), Triunfo en suépoca, Casa de Velázquez-Las Pléyades, Madrid, 1995; Gabriel PlatA, La razón romántica. La cultura del progresismo español a través de Triunfo (1962-1975), Madrid, Biblioteca Nueva, 1999; Albert Forment, José Martínez: la epopeya de Ruedo Ibérico, Barcelona, Anagrama, 2000; Carme FERRÉ, Intel.lectualitat i cultura resistents. Serra d'Or, 1959-1977, Cabrera de Mar, Galerada, 2001; Javier Muñoz Soro, Cuadernos para el diálogo ..., op. cit.; Onésimo Díaz, Rafael Calvo Serer y el grupo Arbor, Valencia, PUV, 2008.

16 José de Cora, Panfletos y prensa antifranquista clandestina, Madrid, Ediciones 99, 1977.

17 Rafael CALvo SERER, La dictadura de los franquistas. El «affaire» del Madrid y el futuro politico, París, Ruedo Ibérico, 1973; Carlos Barrera, El diario Madrid. Realidad y símbolo de una época, Pamplona, Eunsa, 1995.

18 Sobre las estrategias del franquismo para sobrevivir ante el aumento de las corrientes de oposición (politicas e intelectuales) ver Pere Ysàs, Disidencia y subversión. La lucha del régimen franquista por su supervivencia, 1960-1975, Barcelona, Crítica, 2004. 
que influyó entre las clases profesionales, el funcionariado y el mundo universitario. En ellas, aparecen colectivos diversos, pertenecientes a distintas generaciones, ideologías y perfiles profesionales, pero todos ellos coinciden en el objetivo fundamental de la ruptura democrática.

Siguiendo la estela de estas publicaciones, después de la muerte de Franco en 1975 se produjo una explosión de iniciativas editoriales, aparecen innumerables revistas teóricas e ideológicas, aspirantes a ocupar los distintos espacios ideológicos que habían sido reprimidos por el franquismo. Así, de la noche a la mañana, en las estanterías de las librerías aparecieron revistas vinculadas a las diferentes familias comunistas (maoístas, trotskistas, estalinistas, eurocomunistas), publicaciones libertarias, feministas y ecologistas, propuestas que reivindicaban las identidades nacionales de catalanes, vascos y gallegos. De forma no exhaustiva podríamos citar las revistas clásicas del antifranquismo (Cuadernos para el Diálogo, Triunfo, Cuadernos de Ruedo Ibérico) y las nuevas publicaciones de la Transición (Argumentos, Materiales, Sistema, Taula de Canvi, Ajoblanco, El Viejo Topo, Vindicación Feminista, Zona Abierta, etc). Todas ellas reflejan la llegada al espacio público de concepciones de la política y la sociedad inéditas en la vida oficial de los últimos 40 años ${ }^{19}$. Además de su labor de difusión ideológica, estas plataformas ayudaron a tejer redes de sociabilidad y conexiones personales entre los miembros de la oposición al franquismo, facilitando la comunicación entre diferentes sectores abiertos al cambio: políticos de la oposición, líderes sindicales, profesores universitarios, escritores y artistas, etc. Muchos de los protagonistas de las primeras etapas democráticas empezaron su trayectoria en el seno de estas empresas.

La efervescencia ideológica e intensidad de los debates muestra que los intelectuales del periodo tuvieron un papel importante en el proceso democrático, aunque generalmente se haya pasado por alto y sólo recientemente empiece a reivindicarse ${ }^{20}$. Pero aunque su influencia sea innegable, sus acciones resultan, en algunos aspectos, ambivalentes: es cierto que durante la transición los intelectuales lograron articular ese ámbito cultural independiente y alcanzaron un reconocimiento social que antes no tenían, pero simultáneamente su papel en la sociedad empezará a sufrir un proceso de revisión y transformación (este proceso no es exclusivo ni específico de la sociedad española, se produce a nivel internacional), lo que llevará incluso a cuestionar su definición tradicional. En los años 70, los intelectuales se están convirtiendo en otra cosa diferente, ya no responden al modelo instaurado por Zola y asentado por Sartre (y que en España tiene su máxima expresión en Ortega y Gasset) ${ }^{21}$. El denominado «intelectual universal» o «profético» entra en decadencia y se sustituye por lo que M. Foucault, precisamente en estos años, denominó el «intelectual específico». Por tanto, el papel de conciencia moral de la sociedad que, entre otras, asumían personalidades como J. Ruiz-Giménez, E. Tierno-Galván o J. L. Aranguren, empezará a disolverse como consecuencia de las grandes transformaciones sociales y de las mutaciones específicas del campo cultural. Aparecen nuevos profesionales que se especializan en la formación de la opinión pública, y las tareas que antes realizaban los intelectuales del antifranquismo en

19 El papel de la prensa democrática en la Transición a sido estudiado por Isabelle RENAUDET, Un parlement de papier: la presse d'opposition au franquisme durant la dernière décennie de la dictature et la transition démocratique, Madrid, Casa Velázquez, 2003; Juan PecourT, Los intelectuales y la transición política. Un estudio del campo de las revistas políticas en España, Madrid, CIS, 2008, p.

20 Javier Muñoz Soro (ed.), Los intelectuales en la Transición, Ayer, núm. 81, 2011, p. 17-55.

21 Juan Pecourt, «El intelectual: definiciones y polémicas en la Transición política española», Sistema, núm. 223, octubre 2011, p. 109-127. 
exclusiva, ahora tendrán que compartirlas con nuevas figuras ascendentes, como es el caso de los periodistas y expertos, que introducen sus propias perspectivas y discursos. Después de tener una sólida presencia en la esfera pública, los intelectuales del antifranquismo se verán desplazados por los nuevos especialistas ${ }^{22}$.

\section{La reconversión del intelectual universal}

Las causas del cambio que se produce a partir de los años 70 son múltiples y su explicación exigiría un análisis mucho más exhaustivo. Sin duda el cambio político tiene una gran importancia en la aparición de los nuevos roles; de alguna forma, los intelectuales del antifranquismo quedaron desubicados en el nuevo escenario democrático y tienen que amoldarse a las nuevas exigencias de la sociedad. Pero también existen factores específicos del mundo de la cultura, que está inmersa en un intenso proceso de cambio que exceden las explicaciones puramente políticas Las causas «endógenas» son muy diversas, aquí me gustaría centrame en los cambios, a mi juicio decisivos, en el ámbito de los medios de comunicación. Como hemos dicho anteriormente, uno de los pilares de la inteligencia se encuentran en los medios, por ello, su tranformación tendrá graves consecuencias en su posición social y su visibilidad. De hecho, podemos observar que, en los años de la Transición, se produce una «doble mutación mediática» que ayudará a modificar la función social de los intelectuales:

a) En primer lugar, en este periodo se intensifica la liberalización del mercado cultural y el desarrollo de la sociedad de consumo ${ }^{23}$. La consecuencia del proceso será que las publicaciones en las que escribían los intelectuales (que, recordemos, son los instrumentos para intervenir, de manera autónoma, en el debate público) se verán obligadas a competir, en desigualdad de condiciones, con una prensa de masas cada vez menos interesada por las cuestiones ideológicas de fondo y más abierta a las exigencias del consumo cultural.

b) En segundo lugar, también es decisiva la importancia creciente de los nuevos medios de comunicación, lo que supone el paso de la hegemonía del papel (revistas, prensa) a la hegemonía de las patallas (televisión), algo que modifica completamente las características de la producción cultural, la forma y el contenido de los mensajes que pueden difundirse ${ }^{24}$. En un primer momento los intelectuales se mostraron totalmente ajenos al mundo de la televisión, pero con el paso del tiempo no tuvieron más remedio que integrarse en él.

Además de los cambios mediáticos aparecen toda una serie de transformaciones en el ámbito político-cultural que modifican completamente el papel de los participantes en el diálogo social. Entre otros, destacaría la decadencia súbita del marxismo, muy influyente entre la inteligencia antifranquista, que perderá su posición preponderante en el mundo del pensamiento (y en ciertos ámbitos de la acción política) para convertirse en una

22 La pérdida de peso de los intelectuales del antifranquismo se ha acompañado de nuevas perspectivas interpretativas que critican su papel revolucionario en el periodo de la Transición, que no estaba de acorde con los posicionamientos mas moderados de la sociedad española (Gabriel Plata, De la revolución a la sociedad de consumo: ocho intelectuales en el tardofranquismo y la democracia, Madrid, UNED, 2010.

23 Enrique Bustamante, "The state, enterprise culture and the arts» en Helen Graham y Jo Labanyi. Spanish cultural studies: an introduction, Oxford, Oxford University Press, 1995, p. 356-358.

24 Manuel Palacio ArRanz, "La televisión durante el proceso modernizador», en Rafael QuirosaCheyrouze y Muñoz, Prensa y democracia. Los medios de comunicación en la Transición, Madrid, Biblioteca Nueva, 2009, p. 317-333. 
corriente de impacto menor ${ }^{25}$. En muchos casos, durante franquismo tardío, la actividad de los intelectuales se había apoyado en una concepción marxista del compromiso (a este respecto, se reivindicaba repetidamente la idea gramsciana del «intelectual orgánico», y, en el ámbito eurocomunista, se generaron debates importantes en torno a las «fuerzas de la cultura», vinculadas a una concepción marxista de la sociedad y la revolución ${ }^{26}$. La crisis del marxismo pone en cuestión estas definiciones, por lo que se deriva hacia concepciones más vinculadas a la idea del «experto», que aspiran a un cierto grado de desideologización de las funciones intelectuales.

El hundimiento del marxismo se acompaña del ascenso de la social democracia y el liberalismo, que se acercan a la hegemonía política y cultural, y también se relaciona con la difusión de una nueva sensibilidad cultural bautizada con el nombre de posmodernidad, de gran influencia en las décadas siguiente ${ }^{27}$. Una de las características de la nueva cultura posmoderna es precisamente la lucha sin cuartel que realiza contra las grandes teorías que pretenden englobarlo todo, como era el caso del marxismo. Se prefiere la coexistencia de diversas narrativas e interpretaciones, sin una organización jerárquica prefijada; se defienden las perspectivas fragmentadas y particulares de la realidad frente a las visiones holísticas y globales. El clima posmoderno instaurado a partir de los 80 parece contradecir cualquier concepción del intelectual tradicional, percibiéndose como un resto caduco del pasado, una manifestación de elitismo cultural que no ha logrado adaptarse a las nuevas tendencias sociales y culturales, las cuales exigen una mayor diversificación de los discursos y una desmitificación de los antiguos guardianes de la alta cultura (es decir, de los propios intelectuales). La cultura popular, incluso, se convierte en un valor frente a la alta cultura letrada. Ciertos movimientos posmodernos de los 80 , como la conocida movida madrileña y su revista de referencia La Luna de Madrid (1982-1988), se caracterizan por el rechazo total a cualquier forma de compromiso que recuerde a la de los intelectuales tradicionales ${ }^{28}$.

De algún modo, el cuestionamiento posmoderno tiene su razón de ser. Aunque es cierto que los intelectuales del siglo XX se adaptaron perfectamente a la cultura de la letra impresa (y al clima de confrontación ideológica), su capacidad para asimilar la cultura visual (y la creciente desideologización) de las sociedades contemporáneas es bastante más problemática. Como hemos visto en el apartado anterior, los intelectuales del antifranquismo se aglutinaron sobre todo en torno a medios escritos (Cuaderno para el Diálogos, Ruedo Ibérico, Triunfo), y a través de ellos ejercieron la denuncia del poder y la reivindicación del cambio social. Además, las publicaciones funcionaban como ámbitos de socialización, en las que se establecían lazos profesionales pero también personales y emocionales. Junto a las organizaciones políticas, eran el sustento básico de las comunidades críticas del antifranquismo. Paradójicamente, el tiempo vino a demostrar que, como instrumentos

25 José-Carlos Mainer y Santos Julı́, El aprendizaje de la libertad, 1973-1986, Madrid, Alianza, 2000, p. 231.

26 Ver Valeriano BozAl, El intelectual colectivo y el pueblo, Madrid, Alberto Corazón Editor, 1976; Daniel LACALLE, Técnicos, cientificos y clases sociales, Madrid, Guadarrama, 1977; Armando LópEZ SALINAS, La alianza de las fuerzas del trabajo y la cultura, Madrid, Forma Ediciones S.A., 1977.

27 José Tono Martinez, La polémica de la postmodernidad, Madrid, Ediciones Libertarias, 1986; Teresa Vilarós, El mono del desencanto. Una crítica cultural de la Transición española (1973-1993), Madrid, Siglo XXI, 1998.

28 José Luis Gallero, Sólo se vive una vez. Esplendor y ruina de la movida madrileña. Madrid, Ediciones Ardora, 1991; Héctor Fouce y Juan PeCOURT, «Emociones en lugar de soluciones: música popular, intelectuales y cambio politico en la España de la Transición», Trans. Revista transcultural de música, 12,2008 
de acción política, las revistas estaban mejor preparadas para enfrentarse a la Ley de Prensa del 66, con sus formas de censura flexibles y adaptables a las circunstancias, que a las demandas de la sociedad de consumo. Las nuevas pautas de los años 70 difuminan los perfiles de la inteligencia, que no puede competir en la sociedad del espectáculo ni adaptarse a la cultura de la imagen. En este nuevo marco tendrá que medirse con la prensa de masas, cuya pretensión no es tanto participar en los grandes debates ideológicos como difundir información y entretenimiento, de acuerdo a las leyes del mercado (búsqueda de lectores y aumento de las tiradas). Al fin y al cabo, las grandes cabeceras de la prensa diaria son empresas comerciales que actúan en un espacio económico -las revistas del antifranquismo no se regían por los criterios económicos del mercado, y si lo hacían era una decisión estratégica debido a su batalla contra la censura y las imposiciones políticas ${ }^{29}$.

En un espacio de tiempo que podríamos situar entre 1977 y 1979, la mayor parte de las revistas políticas desaparecieron y sus colaboradores más destacados se trasladaron a las tribunas de la prensa diaria. Los periódicos (El País, Diario 16 o La Vanguardia) y la televisión (La Clave), se organizan como conglomerados comerciales y se insertan de forma más clara y precisa bajo las leyes del mercado. Las publicaciones políticas tienen que competir con la nueva prensa de masas en condiciones de desventaja, esto hará que muchas de ellas desaparezcan (como Cuadernos para el Diálogo o Triunfo), o se recluyan en los ámbitos más especializados (Sistema, Mientras Tanto), que por fuerza han de ser minoritarios. En cuestión de unos pocos años, los nuevos medios sustituirán a las revistas de la resistencia política y se convertirán en los instrumentos más importantes para construir la reputación del intelectual democrático.

\section{El intelectual en la sociedad de consumo}

Los nuevos portavoces sociales, o como se les denomina actualmente, los «líderes de opinión», se situarán, a partir de ahora, en las tribunas que proporciona la prensa de masas. Desde los comienzos de la Transición el medio que toma la delantera es el periódico El País, un proyecto formado por gente muy joven, impulsado inicialmente por personas procedentes del franquismo aperturista y la oposición moderada, que por un cúmulo de circunstancias logra imponerse a la prensa tradicional, lastrada durante años por su pasado franquista (como $\mathrm{Ya}$ y $A B C$ ), y a otros proyectos periodísticos de la etapa democrática (como Diario 16) que no llegaron a tener tanto éxito ${ }^{30}$. La cabecera El País forma parte del proyecto empresarial PRISA, nacido en los años 70 y que se convertirá en uno de los grandes conglomerados de la comunicación en España, abriéndose también paso en los mercados globales.

Sin embargo, existe una diferencia básica entre la revistas intelectuales (Cuadernos para el Diálogo, Triunfo) y la prensa de masas de la democracia (El País): las revistas eran proyectos de carácter cultural y político que estaban dirigidas por intelectuales y seguían

29 También el hecho de que la prensa de la democracia se caracteriza por un cierto desdibujamiento ideológico, que se va adaptando a las circunstancias, a diferencia de las posiciones más coherentes, y por tanto, más inflexibles de las revistas antifranquistas. Annelies VAN NoORTwIJK, «La paradójica desaparición de una revista» en Alicia Alted, Paul Aubert (eds.), Triunfo en su época, Madrid, Casa Velázquez-Pléyade Ediciones, 1995, p. 75-91.

30 Gérard Imbert y José Vidal-Beneyto, El País o la referencia dominante, Mitre, Barcelona, 1996; Maria Cruz Seone y Susana Sueiro, Una historia de El País y del Grupo Prisa, Madrid, Plaza y Janés, 2004; Luis Negró AcEdo, El diario El país y al cultura de las élites durante la Transición, Madrid, Foca, 2006. 
criterios intelectuales, mientras que la prensa de masas depende de proyectos periodísticos y empresariales que escapan completamente a la lógica intelectual. Por tanto, el tipo de espacio público que construyeron publicaciones como Triunfo y Cuadernos para el Diálogo es muy diferente al que posibilita El País, La Vanguardia (o más tarde El Mundo). Por una parte, la esfera pública del antifranquismo estaba formada por publicaciones de escasa difusión pero dirigidas por intelectuales, formaban el espacio propicio para la aparición del «intelectual como referente moral» o el «intelectual universal»; por otra, la esfera pública de la democracia, modelada por el mercado económico y el principio de la publicidad, fomentará el desarrollo del «intelectual colectivo» (en el sentido de Aranguren $)^{31}$ y diferentes tipologías del «intelectual mediático», es decir, impulsará la participación pública de profesionales vinculados al mundo del periodismo: articulistas, comentaristas y columnistas, que aumentará el número de los participantes en el debate público al tiempo que éstos pierden el aura carismática de la vieja inteligencia.

La prensa de masas no es el único elemento que trastoca el funcionamiento de las comunidades intelectuales durante la Transición. Además, los medios tradicionales tienen que competir con los nuevos medios, como la radio y la televisión, que en un principio se habían concebido como instrumentos destinados al entretenimiento y la persuasión pero que, poco a poco, asumirán tareas más propias de la acción intelectual. Bajo las nuevas condiciones que imponen los medios audiovisuales, y sobre todo la televisión, las formas de presentación ante los demás tienen una repercusión fundamental en el reconocimiento social de los participantes en el debate público ${ }^{32}$. Tenemos el ejemplo cercano de los «nuevos filósofos franceses», que triunfan en los años 70 (B. H. Lévy, A. Glucksmann, etc.) y desplazan a las generaciones anteriores, quizás más sólidas desde el punto de vista teórico, gracias a su visibilidad mediática ${ }^{33}$. Una parte importante de su éxito se encuentra en la habilidad para manejar los códigos de los nuevos medios: sus apariciones ante las cámaras se asemejaban a las de las estrellas del rock (por ejemplo, el look juvenil y desenfadado de B.H. Lévy en el programa televisivo Apostrophes), proporcionando a sus argumentos una pátina de frescura ante la cual no podían competir los intelectuales clásicos, desarmados frente a los resortes de los nuevos medios.

En España se observa un fenómeno muy parecido al francés, los intelectuales qu'antes se presentaban en las páginas de las revistas tendrán que adaptarse a las nuevas condiciones televisivas, con resultados desiguales. Algunos tendrán una mayor capacidad de adaptación que otros. En 1981 el programa La Clave de J. L. Balbín invitaba al antiguo falangista R. Serrano Suñer, que aparecía por primera vez ante las cámaras de televisión. La conversación entre Balbín y Serrano Suñer es interesante porque evidencia los condicionantes del medio sobre la expresión individual. En un momento de la emisión, el periodista le preguntó por qué no había aceptado anteriormente ninguna invitación de un programa de televisión, y éste le contestó que consideraba que la televisión «no era parte de su mundo», era una cosa para los jóvenes, sentía que no tenía las habilidades requeridas para participar en ella. Posiblemente, con esta respuesta Serrano Suñer expresó de manera directa una experiencia

31 José Luis López Aranguren, «El País como empresa e «intelectual colectivo», El Pais, 7 de junio, 1981. También pueden consultarse José Luis López ARANGUREN, La cultura española y la cultura establecida, Madrid, Taurus, 1977; José Luis López ArANGuren, El oficio del intelectual y la crítica de la crítica, Madrid, Vox, 1979.

32 Pierre Bourdieu, Sobre la televisión, Barcelona, Anagrama, 1997.

33 Teresa CHAPLIN, Turning on the mind. French philosophers and television, Chicago, Chicago University Press, 2007. 
que compartía con otros políticos e intelectuales procedentes de la cultura escrita: la gran incomodidad que sentían ante la naturaleza de la televisión, a pesar de su potencial para alcanzar una audiencia masiva. Otros, sin embargo, se sentían mucho más cómodos ante las cámaras y pedían ser invitados por Balbín porque «daban mucho juego» ${ }^{34}$. La filosofía y el pensamiento se convertían en un entretenimiento para las masas.

Por tanto, las consecuencias de la doble mutación mediática es la progresiva transformación del «intelectual tradicional», el que escribe análisis en profundidad, publica ensayos especializados, firma peticiones y manifiestos, en «intelectual mediático», que se especializa en los artículos de prensa y puede adaptar su discurso a las pautas efímeras y fragmentarias de la televisión. Es necesario adaptar el discurso al medio: transmitir ideas sencillas y chocantes, como si fueran lemas y titulares (ejercer el «pensamiento rápido»). Esta norma básica de la televisión contradice la morosidad y la paciencia que son propias de la reflexión intelectual (el «pensamiento lento») en favor de la espontaneidad, la inmediatez y la capacidad de impacto instantáneo ${ }^{35}$. Los mensajes que anteriormente aspiraban a la universalidad, ahora mostrarán unos contornos mucho más modestos. Este proceso de adaptación al medio convierte al intelectual en una celebridad más en un mundo de celebridades ${ }^{36}$.

El nuevo escenario obligará a los representantes de la cultura a redefinir las formas de comunicación con la sociedad. Las respuestas son bastante diversas, aparecen diferentes estrategias «mediáticas» que podemos, incluso, diferenciar de las estrategias estrictamente «ideológicas». Por una parte, como ya hemos comentado, los posicionamientos clásicos de tipo universal (Tierno, Marías, Aranguren) tienden a extinguirse, el impacto de sus pronunciamientos se reduce severamente en el nuevo entorno mediático de la prensa de referencia y la televisión. La comunicación directa que lograron establecer con públicos restringidos, a través de los canales que proporcionaban las publicaciones del antifranquismo, se pierde con la mercantilización cultural y la promoción del espectáculo. Al mismo tiempo, aparecen nuevas formas de participación que no responden a los modelos clásicos y que podemos sintetizar (de una forma general y aproximativa) en tres grandes tendencias: (a) los que abrazan alegremente las posibilidades ofrecidas por la cultura periodística y las utilizan para difundir sus ideas a públicos amplios, (b) los que reconocen la importancia de los medios, pero tratan de adaptarse a ellos actuando con cierta cautela, y finalmente (c) los que optan por la retirada y por restringir su participación al ámbito de la academia, con la esperanza de ejercer una influencia indirecta y a largo plazo sobre la sociedad $^{37}$. Todos ellos reinterpretan de alguna forma el papel del intelectual clásico y lo adaptan al escenario que se abre a partir de los años 80 . Veamos los tres modelos en más detalle, centrándonos en tres autores paradigmáticos que los representan: F. Savater, E. Trías, y J. Muguerza:

a) En primer lugar, podríamos identificar a aquellos que se adaptan perfectamente a las nuevas peculiaridades del entorno mediático, porque tienen la capacidad de moldear sus mensajes de acuerdo a las expectativas de los públicos a los que van dirigidos. Éste es

34 Entrevista a José Luis BALBiN, programa «España en la Memoria», radio Intereconomía, emitido el 4 de febrero de 2012.

35 Pierre Bourdieu, Sobre la televisión, Barcelona, Anagrama, 1997.

36 Zygmunt BAUMAN, Legislators and interpreters: on modernity, postmodernity and intellectuals, Cambridge, Polity Press, 1987.

37 La distinción entre los tres tipos se basa en una categorización similar realizada por R. Rieffel en Francia. Ver Rémy RIEFFEL, «Du vedettariat médiatique», Hermès, núm.4, Paris, Ed. du CNRS, 1989. 
el grupo de los intelectuales mediáticos en el sentido pleno de la palabra. En el contexto español, dentro de los especialistas en la utilización de los medios, el caso de F. Savater es ilustrativo. El filósofo vasco domina con igual maestría los medios escritos y audiovisuales, donde sus habilidades retóricas son siempre impactantes y accesibles a la mayoría ${ }^{38}$. Es un colaborador habitual del diario de referencia de la prensa española, El Pais, y cofundador de la revista Claves de la Razón Práctica, junto al periodista J. Pradera, que aspira a difundir los debates académicos a un público generalista. Además publica asiduamente libros que tienen una amplia difusión. Savater combina su presencia mediática, adaptada a los cánones de los medios actuales, con unas formas de participación que recuerdan a la inteligencia clásica (Aranguren, etc.). Suele intervenir en los grandes debates de actualidad, y sus opiniones se vierten en cuestiones como el nacionalismo y el terrorismo, aunque tampoco evita otros temas que afecten a la opinión pública. La claridad de su compromiso público se muestra, incluso, en su reciente colaboración con el partido político Unión Progreso y Democracia. Su condición como intelectual mediático puede observarse en los premios recibidos: Premio Nacional de Literatura (1981), Premio Anagrama (1982) y Premio Planeta (2008).

b) En segundo lugar, podemos identificar las posiciones de los autores que mantienen un mayor alejamiento frente a los medios, aunque no rechazan la participación ocasional en temas que consideran de especial relevancia. Este podría ser el caso del filósofo barcelonés E. Trías. La comparación de las trayectorias entre Savater y Trías (que F. Vázquez ha estudiado detenidamente desde la perspectiva de sus respectivas obras filosóficas) $)^{39}$, refleja la divergencia de estrategias mediáticas que comentamos. Ambos autores pertenecen a la misma generación, se dieron a conocer en la misma época y emprendieron proyectos teóricos similares; mientras el primero se considera un «mitómano ilustrado», el segundo afirma ser un «exorcista ilustrado». Pero a diferencia de Savater, Trías mantiene una vinculación mucho más estrecha con el ámbito académico, ha desarrollado un discurso más hermético y cerrado dirigido a los especialistas. La participación pública de Trías es más selectiva, no se prodiga tanto como Savater, y suele centrarse en programas de divulgación filosófica y otros temas específicos, como el lugar de las humanidades en el sistema educativo. A pesar de su carácter selectivo, la vinculación de Trías con los medios también es importante, ya que forma parte del Consejo Editorial del diario El Mundo. Pero, en líneas generales, los premios recibidos por el filósofo catalán -Premio Nueva Crítica (1975), Premio Anagrama (1983), Premio Nacional de Ensayo (1995), Premio Internacional Friedrich Nietzsche (1995)- muestran un perfil más orientado a la academia que a los medios.

c) Finalmente, en tercer lugar, pueden señalarse aquellos casos que rehúyen la visibilidad mediática y pretenden ejercer la influencia desde los espacios propios del pensamiento, por lo que tienden a mantenerse alejados del periodismo (tanto de las tribunas periodísticas como de las apariciones frecuentes en la televisión). Este sería el caso de Javier Muguerza, un destacado representante de la filosofía contemporánea española y promotor de la filosofia analítica, la teoría crítica y las corrientes morales y políticas anglosajonas y alemanas. Muguerza ha logrado el prestigio y el reconocimiento de los pares, pero luego no ha pretendido acceder a las plataformas ofrecidas por la prensa de referencia o la televisión. Dirige una revista puntera en el terreno académico de la filosofía, Isegoría:

38 Paul Julian SMITH, The moderns: time, space and subjectivity in contemporary Spanish culture, Oxford, Oxford University Press, 2000.

39 Francisco Vázquez Garcia, La filosofia española. Herederos y pretendientes. Una lectura sociológica (1963-1990), Madrid, Abada Editores, p. 315-336. 
Revista de Filosofia Moral y Política, y también ha sido director del Instituto de Filosofia del CSIC entre 1986-1990. A diferencia de Trías, y sobre todo de Savater, Muguerza no tiene vínculos relevantes con los medios de comunicación, salvo algunas apariciones ocasionales. Muguerza es el ejemplo de «intelectual inorgánico» que descarta cualquier tipo de asociación con los poderes sociales, entendiendo por éstos tanto las fuerzas políticas y económicas como las mediáticas; en realidad, su pretensión es ejercer la influencia a través de la auctoritas y no la potestas. En un debate con Aranguren, ante la incertidumbre del intelectual contemporáneo, o las dificultades que muestra esta figura en las condiciones del presente, Muguerza comentaba que, si finalmente se certificara la muerte de los intelectuales, al menos habría que «procurarles una muerte digna» ${ }^{40}$. Esta afirmación parece sugerir que, dadas ciertas condiciones, la tarea del intelectual es simplemente impracticable y es mejor dedicarse a otros menesteres. En su caso, el reconocimiento exclusivo de los especialistas y la ausencia de un perfil mediático se refleja en la no-obtención de premios y honores de impacto mediático, algo que sí se observa, en mayor o menor medida, en los casos anteriores.

\section{Conclusión}

Muchas interpretaciones históricas de los intelectuales terminan con un mensaje de despedida. La línea argumental sería más o menos la siguiente: sí, es cierto, los representantes del pensamiento y las letras fueron influyentes a lo largo del siglo XX, tuvieron sus momentos gloriosos en el periodo de entreguerras (años 20 y 30 ) y durante la Guerra Fría (años 40-60), pero a partir de entonces su papel en la sociedad decayó de forma repentina. A partir de la década de los 70 ya no surgen grandes figuras que puedan compararse con los intelectuales clásicos. La bibliografía más reciente está plagada de títulos apocalípticos como «muerte de los intelectuales», «final de los intelectuales»o «desaparición de los intelectuales», otras veces se plantean preguntas de carácter mas retórico como «¿donde están los intelectuales?», «¿donde se encuentra el pensamiento crítico?» que parten también de la premisa de su ausencia. Todos estos planteamientos surgen de una definición muy estricta del intelectual, que hemos heredado sobre todo de la cultura francesa (el «intelectual universal» que interviene públicamente en el nombre de una serie de valores universales). Sin duda ese actor social tiende a desaparecer, aunque también reaparezca en momentos insospechados, sobre todo en sociedades en donde se mantiene el autoritarismo y el control de los medios (Salman Rushdie en el mundo musulmán, Ai Wei Wei en China, etc). En las sociedades occidentales democráticas, donde la censura de las opiniones no es una opción viable para las autoridades políticas, han surgido otras fuerzas que modelan y prefiguran los discursos intelectuales. Estas fuerzas se asientan en las características propias de la sociedad de consumo, cuya influencia en la inteligencia suele llegar mediada por la estructura de los medios de comunicación de masas, el instrumento esencial para llegar al público generalista. Por esta razón, para capturar las nuevas tipologías hay que analizar lo que pasa en los medios actuales.

El caso español muestra elementos comunes y diferenciales con otras sociedades europeas. En nuestro país, como en otros países europeos, los intelectuales disfrutaron de momentos

40 Pablo Ródenas, «Un diálogo entre perplejos. A la busca del individuo polí (é) tico y comunipolita» en Roberto R. Aramayo y J. Francisco Álvarez (eds.), Disenso e incertidumbre. Un homenaje a Javier Muguerza, Madrid, Plaza y Janés, 2006, p. 159-195. 
álgidos en el periodo de entreguerras (años 30) y, décadas más tarde, experimentaron un proceso de reconversión acelerada (años 70 y 80). Pero a su vez el fenómeno también muestra rasgos propios y distintivos que son el resultado del peculiar recorrido histórico de la sociedad española, de sus turbulencias políticas y tradiciones culturales. El final de la guerra civil fue un momento claro de ruptura (los intelectuales modernos, a pesar del retraso histórico de la sociedad española, había tenido un fuerte impacto), dando lugar a un escenario inédito caracterizado por la ausencia de los pronunciamientos públicos de la inteligencia. Las características políticas (régimen dictatorial) y culturales (rechazo total de la modernidad) del franquismo, especialmente en su primera época, obstaculizan su presencia en la sociedad civil.

Más tarde, de forma lenta y progresiva, las primeras generaciones de intelectuales antifranquistas ayudaron a reconstruir la esfera pública, el legado de la autonomía y los valores democráticos. Sin embargo, en el momento que se culmina el proceso, que coincidiría con el periodo de la transición, el papel de los intelectuales sufrirá una gran transformación. En este caso ya no se trata de un fenómeno exclusivamente local sino que tiene una impronta global. Las grandes transformaciones sociales, económicas y culturales del periodo van a transformar de forma irreversible sus características y funciones. Después de la transición se recupera la autonomía de la esfera pública, desaparece la censura política, pero aparecen nuevas fuerzas sociales que condicionan su posición social. Las nuevas fuerzas ejercen presiones de carácter invisible e impersonal y proceden sobre todo de un mercado económico que gradualmente ha ido colonizando el mundo de la cultura. En el nuevo escenario, la comercialización, la fragmentación, la novedad y el espectáculo, se convierten en las pautas esenciales de la difusión cultural. Este panorama inducirá a la mutación acelerada de las tareas intelectuales, a la redefinición de los roles asignados. En lugar de desaparecer, las funciones intelectuales se fragmentan y diversifican. Los nuevos intelectuales se dirigirán a públicos cada vez más específicos, perdiendo poco a poco la capacidad de conectar con el conjunto del público educado o atento. Su vinculación con los medios de comunicación, su manera de presentarse públicamente ante la sociedad civil, se constituirá, a partir de ahora, en un criterio básico de demarcación.

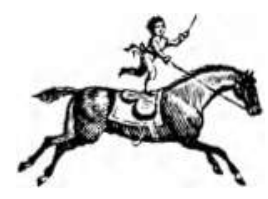

